\title{
Susceptibility of blue-winged teal, gadwall, and lesser scaup ducklings to experimental infection with Streptocara crassicauda
}

\author{
R. J. A. LABerge AND J. DANiel MCLAughlin ${ }^{1}$ \\ Department of Biology, Concordia University, 1455 de Maisonneuve Blvd. W., Montréal, Quebec, Canada H3G IM8
}

Received September 4, 1990

LABERGe, R. J. A., and MCLaughlin, J. D. 1991. Susceptibility of blue-winged teal, gadwall, and lesser scaup ducklings to experimental infection with Streptocara crassicauda. Can. J. Zool. 69: 1512-1515.

Blue-winged teal, gadwall, and lesser scaup ducklings were exposed experimentally to identical doses of Streptocara crassicauda larvae. The heaviest infections developed in the teal. Gadwall were also highly susceptible and infection levels were generally similar to those in teal. Lesser scaup developed comparatively light infections. Lesions were restricted to the gizzard and occurred in the softer areas of the lining under the tendinous surfaces. Nematodes were generally confined to the lesions in scaup, but not in teal or gadwall. In these two species, they were also found elsewhere under the softer portions of the lining and, to a lesser extent, under the grinding plates. Teal and gadwall developed more and larger lesions because of the greater number of nematodes that established. When corrected for worm number, no difference in lesion size was found among the three species.

Laberge, R. J. A., et MCLaughlin, J. D. 1991. Susceptibility of blue-winged teal, gadwall, and lesser scaup ducklings to experimental infection with Streptocara crassicauda. Can. J. Zool. 69 : 1512-1515.

Des canetons de sarcelles à ailes bleues, de canards chipeaux et de petits morillons ont été exposés expérimentalement à des nombres identiques de larves de Streptocara crassicauda. C'est chez les sarcelles que les infections se sont avérées les plus graves. Les canetons du canard chipeau étaient aussi très sensibles et leurs infections étaient généralement aussi graves que celles des sarcelles. Les morillons n'avaient en comparaison que des infections bénignes. Les lésions étaient restreintes au gésier et affectaient les régions plus molles de la paroi sous les surfaces tendineuses. Les nématodes restaient généralement dans les lésions chez les morillons, mais chez les sarcelles et chez les chipeaux, ils se retrouvaient aussi ailleurs, sous les portions molles de la paroi et, en moins grands nombres, sous les plaques broyeuses. Les lésions étaient donc plus nombreuses et plus grandes chez les sarcelles et chez les chipeaux à cause du plus grand nombre de nématodes qui réussissaient à s'établir. Après incorporation, dans l'analyse, d'une correction en fonction du nombre de vers, il appert que la taille des lésions ne diffère pas d'une espèce à l'autre.

[Traduit par la rédaction]

\section{Introduction}

Streptocara crassicauda (Creplin, 1829) is a cosmopolitan nematode that occurs predominantly in Anatidae (McDonald 1969). It has been reported frequently in surveys of waterfowl helminths in Canada (e.g., Cornwell and Cowan 1963; Gibson 1968; Crichton and Welch 1972; Bishop and Threlfall 1974; Bain and Threlfall 1977; Bourgeois and Threlfall 1982; McLaughlin and McGurk 1987) and in the United States (e.g., Quortrup and Schillinger 1941; Kinsella and Forrester 1972; Wilkinson et al. 1977; Thul et al. 1985; Wallace and Pence 1986). Although normally found under the gizzard lining, $S$. crassicauda has also been reported from lesions in the esophagus (Boughton 1969; Mason 1988) and, possibly, at the junction of the proventriculus and gizzard (Sterner and Stackhouse 1987). Garkavi (1949) and Kovalenko (1961) (Soviet Union), Boughton (1969, England), Sterner and Stackhouse (1987, United States), and Mason (1988, Australia) have implicated this helminth in the deaths of waterfowl.

Recent studies on the gizzard worm infections in fall migrant ducks at Delta, Manitoba, Canada, revealed that the prevalence of $S$. crassicauda varied extensively among host species. Lesser scaup (Aythya affinis), a diving species, had the highest prevalence of infection among the 13 species examined. Blue-winged teal (Anas discors) had the highest prevalence among dabbling species, and gadwall (Anas streptera), also a dabbling species, had the lowest prevalence of any host species examined (McLaughlin and McGurk 1987). The difference in infection levels among these host species was interpreted as a reflection of the importance of amphipods, the intermediate host of this helminth, in their diets. Lesser scaup feed almost exclusively on amphi-

'Author to whom all correspondence should be sent. pods (Rodgers and Korschgen 1966; Bartonek and Hickey 1969; Dirschl 1969). Blue-winged teal apparently use amphipods in proportion to their availability but not as a preferred food (Swanson et al. 1974). Gadwall seldom eat amphipods beyond the first few weeks of life (Sugden 1973).

This study examines the susceptibility of lesser scaup, bluewinged teal and gadwall ducklings to experimental infections of $S$. crassicauda. The objectives were threefold: (i) to determine if the prevalence of the infections seen among these species in wild populations does, in fact, reflect different exposure through diet or whether dabbling species are intrinsically more refractive to $S$. crassicauda; (ii) to evaluate the importance of blue-winged teal and gadwall in the transmission of this helminth; and (iii) to compare the lesions caused in each species in an attempt to evaluate the pathogenicity of this helminth in these waterfowl hosts.

\section{Materials and methods}

Blue-winged teal, gadwall, and lesser scaup ducklings were hatched at the Delta Waterfowl and Wetlands Research Station from eggs collected in the wild and reared in parasite-free conditions. Food (18\% laying feed, Nutribec Ltd., Montréal) and water were available ad libitum.

Infective larvae were reared in Hyalella azteca (Amphipoda), following procedures described in Laberge and McLaughlin (1989). Larvae were $35 \pm 5$ days old when used. Prior to use, each amphipod was examined microscopically to determine the number of larvae present. Each duckling was then intubated with a sufficient number of amphipods to produce a dose of 20 larvae.

Two groups of ducklings were exposed in successive years. Group 1 consisted of 10 teal, 8 gadwall, and 9 scaup. Group 2 consisted of 12 ducklings of each species. With the exception of the scaup in group 1, which were 3 weeks old, all ducklings were 5-7 weeks old when exposed. 
Ducklings were isolated individually $(4-5 \mathrm{~h})$ in wire-bottom cages for fecal collection. Water was provided ad libitum. For group 1, six ducklings of each species were chosen at random and isolated on days $7,13,21$, and 28 post exposure. All ducklings in group 2 were isolated on days $7,10,13,16,19$, and 21 . Feces were processed using an acid-ether sedimentation technique (Garcia and Ash 1979) and the sediment was examined microscopically for eggs.

Ducklings in group 1 were necropsied 42 days after exposure. The esophagus, proventriculus, and gizzard were removed and separated. The esophagus and proventriculus were slit open and the mucosal surface was examined, under magnification, for nematodes. The gizzards were opened by lengthwise cutting from the junction of the proventriculus through the left tendinous surface to the caudal sac (terminology follows McLelland 1979). The lining was removed and its undersurface and the muscularis were searched microscopically for parasites. Work on group 1 ducklings was limited to recovery of any nematodes present.

Ducklings in group 2 were necropsied on day 23 post exposure. Examination procedures were as outlined above but with the following modifications. Prior to removal, the lining was photographed under a glass plate that had a $1.2 \mathrm{~mm}$ square grid superimposed on it. This provided a means to quantify the surface area and any lesions present. The area between the grinding plates on the ventriculopyloric side of the gizzard (i.e., the area under the right tendinous surface) was designated as site 1 and the opposite side (i.e., the area under the left tendinous surface) as site 2 (results from group 1 indicated that lesions would be located in these areas). The lining was removed in sections: the softer portions first, followed by the grinding plates. The number of nematodes present and their location were recorded.

Statistical analyses were performed using programs in Number Cruncher Statistical System Version 5.01 (available from Dr. J. L. Hintze, 865 East 400 North, Kaysville, Utah). Significance levels were set at $P<0.05$. Variation, in the text, is expressed as the mean $\pm \mathrm{SE}$.

\section{Results}

The teal developed the heaviest infections in each group (Table 1). Significantly more teal $\left(\chi^{2}=11.82, \mathrm{df}=1, P<\right.$ $0.001)$ and gadwall $\left(\chi^{2}=4.89, \mathrm{df}=1, P<0.05\right)$ than scaup were infected in group 1 , but no differences were found among species in group 2 . Analysis of variance revealed that teal in group 1 had a greater mean intensity than gadwall $(F=7.12$, $\mathrm{df}=2,12, P<0.01$ ) and, in group 2 , both teal and gadwall had a greater mean intensity than $\operatorname{scaup}(F=13.1, \mathrm{df}=2,30, P<$ $0.001)$.

Comparisons between groups revealed generally higher infection levels in each species in group 2 (Table 1). Significantly more gadwall $\left(\chi^{2}=5.29, \mathrm{df}=1, P<0.05\right)$ and scaup $\left(\chi^{2}=8.41, \mathrm{df}=1, P<0.01\right)$ were infected in group 2 . The mean intensity in gadwall in group 2 was greater $(F=14.96$, $\mathrm{df}=1,15, P<0.001$ ) than in group 1 .

One teal and four gadwall in group 1 passed eggs. Eggs were found in teal droppings on days 21 and 28 . The gadwall passed eggs on days 13,21 , and 28 . When necropsied on day 42 , these ducklings were either uninfected or had single-worm or singlesex infections. Nine teal and 10 gadwall in group 2 passed eggs. Eggs were first seen in droppings from teal on day 16. The first eggs from gadwall were found on day 13. Teal and gadwall that did not pass eggs had single-sex infections at necropsy on day 21 . None of the scaup in either group passed eggs. The single infected scaup in group 1 and seven of the nine infected scaup in group 2 harboured single-sex infections at necropsy.

All nematodes were found under the gizzard lining. There was no evidence of invasion of the muscularis, although areas where worms were present were inflamed. Neither worms nor lesions occurred in the esophagus or proventriculus. Typical lesions appeared as darkened, rough, raised areas in the softer portions
TABLE 1. Summary of Streptocara crassicauda infections in experimentally exposed blue-winged teal, gadwall, and lesser scaup ducklings

\begin{tabular}{lccc}
\hline \hline & Teal & Gadwall & Scaup \\
\hline Group 1 & & & \\
$\quad$ Exposed & 10 & 8 & 9 \\
$\quad$ Infected & 9 & 5 & 1 \\
$\quad$ Mean intensity \pm SE & $7.1 \pm 1.9$ & $1.2 \pm 0.4$ & 2 \\
Group 2 & & & \\
$\quad$ Exposed & 12 & 12 & 12 \\
$\quad$ Infected & 12 & 12 & 9 \\
$\quad$ Mean intensity \pm SE & $11.1 \pm 1.4$ & $9.5 \pm 1.4$ & $2.1 \pm 0.4$ \\
\hline
\end{tabular}

of the lining (sites 1 and 2). Eleven teal and 7 gadwall had lesions in both sites; lesions in scaup were restricted to site 1 . An average of $64 \%$ of the worms in teal and $56 \%$ in gadwall were associated with the actual lesions compared with $92 \%$ in scaup. The remainder were found elsewhere, under the softer portions of the lining surrounding the grinding plates, or under the plates themselves. All of the teal and gadwall and 8 scaup had nematodes in the soft portions. Significantly more teal (9) and gadwall (10) than scaup (2) had nematodes under the plates $\left(\chi^{2}=11.56, \mathrm{df}=2, P<0.01\right)$. The mean number of nematodes under the softer portions of the lining was significantly greater than under the plates in teal $(8 \pm 1.1$ vs. $4.2 \pm 0.7, P<$ $0.05)$ and in gadwall $(6.8 \pm 1.1$ vs. $3.2 \pm 0.6, P<0.01)$ but not in scaup ( $2.3 \pm 0.5$ vs. 1$)$. The number of nematodes under the plates was positively and significantly correlated with the total load in gadwall $\left(P<0.05, r^{2}=0.45\right)$ and positively correlated in teal $\left(r^{2}=0.22\right)$.

Lesion area increased significantly with increasing worm loads in each species. The regression equations relating lesion area $\left(\mathrm{mm}^{2}\right)$ and the number of $S$. crassicauda present in each lesion for the three species are as follows: teal $(n=20), Y=$ $13.82+5.01 X, r^{2}=0.48, P<0.001$; gadwall $(n=18), Y=$ $15.61+5.36 X, r^{2}=0.47, P<0.001$; scaup $(n=7), Y=$ $1.37+7.85 X, r^{2}=0.73, P<0.01$. Analysis of covariance revealed that the relationship between lesion size and the number of nematodes present was similar for all three species $(F=0.22$, $\mathrm{df}=2,42, P=0.8$ ).

The mean total lesion area per duckling and the mean lesion area were significantly greater in teal and gadwall than in scaup (Table 2). Both teal and gadwall had more nematodes associated with each lesion than scaup but the numbers were not significantly greater. When lesion area was corrected for the number of nematodes per lesion, no differences were detected among the three species. Total lesion area, expressed as a percentage of the gizzard area, differed significantly among all three species.

\section{Discussion}

Blue-winged teal and gadwall are highly susceptible to $S$. crassicauda. Neither species has an innate resistance to this helminth and the high percentage of the infective dose that established in group 2 ducklings suggests that neither species is capable of limiting establishment of $S$. crassicauda to any extent. The levels of infection reported in these two species in natural conditions (McLaughlin and McGurk 1987) do indeed seem to reflect their degree of contact with the infective pool through the use of amphipods rather than an intrinsic resistance to this helminth. Some caution is necessary in this interpretation, 
TABLE 2. Lesion and gizzard parameters of blue-winged teal, gadwall, and lesser scaup infected with Streptocara crassicauda

\begin{tabular}{|c|c|c|c|c|c|c|c|c|c|}
\hline & \multicolumn{2}{|c|}{ Teal } & \multicolumn{2}{|c|}{ Gadwall } & \multicolumn{2}{|c|}{ Scaup } & \multicolumn{2}{|c|}{$F$} & \multirow[b]{2}{*}{$P$} \\
\hline & Mean & SE & Mean & SE & Mean & SE & df & Ratio & \\
\hline Mean lesion area $\left(\mathrm{mm}^{2}\right)$ & 30.3 & $(2.9)$ & 33.1 & $(3.1)$ & 15.1 & $(4.7)^{*}$ & 2,45 & 5.32 & $<0.01$ \\
\hline Corrected area $\left(\mathrm{mm}^{2}\right)$ & 10.7 & $(0.9)$ & 11.3 & $(0.9)$ & 8.8 & $(1.4)$ & 2,45 & 1.07 & ns \\
\hline No. of nematodes/lesion & 3.3 & $(0.4)$ & 3.3 & $(0.4)$ & 1.8 & $(0.6)$ & 2,45 & 2.47 & ns \\
\hline Total lesion area $\left(\mathrm{mm}^{2}\right)$ & 57.7 & $(4.8)$ & 52.4 & $(4.6)$ & 15.1 & $(5.6)$ & 2,28 & 19.09 & $<0.001$ \\
\hline Gizzard area $\left(\mathrm{mm}^{2}\right)$ & 579 & $(27.9)^{*}$ & 919 & $(26.8)$ & 927 & $(32.8)$ & 2,28 & 48.64 & $<0.001$ \\
\hline Lesions/gizzard (\%) & 10.1 & $(0.7)^{*}$ & 5.7 & $(0.6)^{*}$ & 1.6 & $(0.8)^{*}$ & 2,28 & 35.52 & $<0.001$ \\
\hline
\end{tabular}

*Duncan's multiple range test; significantly different from otiıer species.

however, because previous studies (Laberge and McLaughlin 1989) and our results from teal and gadwall of group 1 suggest that some worms are lost by day 42 . Ducklings that had passed eggs had lost part or all of their worm load by the time they were necropsied. Infection levels were lower in teal of group 1, but not significantly so, suggesting that if loss occurred, it was minimal. On the other hand, the four gadwall in group 1 had clearly lost part of their loads by the time they were necropsied. This raises the possibility that infections acquired early in the summer may have been lost by fall.

Although they are potential contributors to local infective pools, it seems blue-winged teal and gadwall, and dabbling species in general, are unable to maintain this parasite on large wetlands. Only 11 of 546 resident dabbling ducks (five species) examined in the Delta Marsh in three separate studies were infected with S. crassicauda (Buscher 1965, 1966; Crichton and Welch 1972). Local foci doubtless exist, but transmission is - ineffective. While transmission among dabbling species remains a possibility, particularly between ducks sharing small permanent wetlands such as sloughs, we believe it is essentially the portion of dabbling duck populations that overlaps areas used extensively by lesser scaup (or perhaps other carnivorous waterbirds) that is likely to be exposed under natural conditions. Thus blue-winged teal and gadwall are suitable hosts in the sense defined by Holmes (1979); they are readily susceptible and capable of supporting patent infections but play a minor role in maintaining the nematode population.

Fewer scaup became infected and, in group 2, only $8 \%$ of the larvae administered established. This was unexpected, as lesser scaup had the heaviest infections of all species examined during fall migration (McLaughlin and McGurk 1987). Amphipods, which serve as the intermediate host of S. crassicauda, are the major prey of lesser scaup (Rodgers and Korschgen 1966; Bartonek and Hickey 1969; Dirschl 1969), and it is reasonable to assume that scaup are exposed continuously to this helminth. The thrust of evolution on the part of the host is defensive, producing at least partial incompatibility with the parasite, thereby making establishment difficult after recruitment (Esch et al. 1977). An example of this is a study by Austin and Welch (1972), who found that shovellers (Anas clypeata) were refractive to experimental infection with Echinuria uncinata while other species were readily infected. As shovellers feed extensively on cladocerans, the major intermediate host of $E$. uncinata, they should be exposed frequently to this helminth. Austin and Welch (1972) interpreted these results as evidence that selection had favoured the evolution of resistance in this host. Streptocara crassicauda is not as pathogenic as E. unicata and lesser scaup were not refractive to experimental infection with it. However, consistently lighter infections established than in either of the dabbling species, suggesting that some mechanism limiting the establishment of $S$. crassicauda may exist in lesser scaup. It is unlikely that such a mechanism would evolve in species that have limited contact with this parasite.

Although teal and gadwall had more and significantly larger lesions than lesser scaup, the number of nematodes per lesion, the corrected lesion area, and the relationship between lesion area and the number of nematodes present was similar among the three species. Individual nematodes appear to cause the same amount of damage to the gizzard lining regardless of host species. The larger lesions seen in the dabblers were due to the cumulative effects of the larger worm loads in these species. Regression of lesion area on the number of nematodes present in the lesion accounted for less than half of the variation in teal and gadwall. Nematodes were not restricted to the lesions in these species, and individual worms entering or dispersing from the lesion site may have been a major source of the variation observed.

While $S$. crassicauda has been reported from sites other than the gizzard (see above), infections in our study were limited to the gizzard. Although worms were found under all regions of the lining, the majority of worms and all of the lesions were associated with the softer portions. The number of nematodes under the grinding plates increased with worm burden, however, the low $r^{2}$ values in teal and gadwall suggest that other factors, in addition to worm burden, also affect the distribution of $S$. crassicauda under the lining in these species.

Our data suggest that $S$. crassicauda is unlikely to cause the esophageal and proventricular lesions reported in other studies. A similar species, Streptocara incognita Gibson, 1968, occurs in the esophagus and proventriculus as well as in the gizzard. Lancaster (1973) found this species in the crop of a muscovy duckling, and Sterner and Stackhouse (1987) found mixed infections of $S$. crassicauda and $S$. incognita in mallards with lesions in both the proventriculus and gizzard. Unfortunately, the specimens from the mallards had been pooled prior to identification and it was not possible to determine from which site each species came. Where specimens from lesions in sites anterior to the gizzard have been reexamined (e.g., Karlovic et al. 1959; Boughton 1969), they have been identified as $S$. incognita rather than S. crassicauda (Gibson 1968 and Lancaster 1973, respectively) as reported in the original study. A report by Mason (1988) notwithstanding, it seems likely that lesions in the digestive tract anterior to the gizzard, in Anatini at least, are due to $S$. incognita and not $S$. crassicauda. Whether this is the case 
in the Mergini (e.g., Somateria and Melanitta), as reported by Bishop and Threlfall (1974) and Bourgeois and Threlfall (1982), requires further study.

Comparable studies on $S$. incognita are needed to assess its significance as a potential pathogen of waterfowl. It appears from our results that this species is of potentially greater consequence to waterfowl populations than is $S$. crassicauda.

\section{Acknowledgments}

We thank Dr. Bruce Batt, former director, and Mr. Ken Risi, waterfowl technician, Delta Waterfowl and Wetlands Research Station, for their cooperation and assistance during this project. Mr. E. F. Whitney, Canadian Wildlife Service, kindly provided the necessary permits to collect and examine the ducklings. Irene Menaggia, Concordia University, generously translated the Russian articles. Mr. Bruce Reid, Verdun, Quebec, provided the goldeneyes that served as a source of $S$. crassicauda in 1988. This work was supported by funds provided by the Faculty of Arts and Sciences, Concordia University.

Austin, F. G., and Welch, H. E. 1972. The occurrence, and pathogenicity of Echinuria uncinata (Rudolphi, 1819) Soloviev, 1912 (Spirurida, Nematoda) in waterfowl at Delta, Manitoba. Can. J. Zool. 50: $385-393$.

BAIN, G. A., and Threlfall, W. 1977. Helminth parasites of hooded mergansers, Lophodytes cucullatus (L.), from Ontario. Proc. Helminthol. Soc. Wash. 44: 219-221.

BARTONEK, J. C., and HiCKEY, J. J. 1969. Food habits of canvasbacks, redheads, and lesser scaup in Manitoba. Condor, 71: 280-290.

Bishop, C., and Threlfall, W. 1974. Helminth parasites of the common eider duck, Somateria mollissima (L.), in Newfoundland and Labrador. Proc. Helminthol. Soc. Wash. 41: 25-35.

Boughton, E. 1969. On the occurrence of esophageal worms, Streptocara crassicauda in ornamental ducks in Hampshire. J. Helminthol. 43: $273-280$.

BouRGEOIS, C., and THRELFALL, W. 1982. Metazoan parasites of three species of scoter (Anatidae). Can. J. Zool. 60: 2253-2257.

BuSCHER, H. N. 1965. Dynamics of the intestinal helminth fauna of three species of ducks. J. Wildl. Manage. 29: 772-781.

- 1966. Intestinal helminths of the blue-winged teal, Anas discors L., at Delta, Manitoba. Can. J. Zool. 44: 113-116.

Cornwell, G. W., and Cow AN, A. B. 1963. Helminth populations of the canvasback, (Aythya valisineria) and host-parasite-environmental relationships. Trans. North Am. Wildl. Nat. Resour. Conf. 28: 173-199.

Crichton, V. F. J., and WelCh, H. E. 1972. Helminths from the digestive tracts of mallards and pintails in the Delta Marsh, Manitoba. Can. J. Zool. 50: 633-637.

DiRSCHL, H. 1969. Foods of lesser scaup and blue-winged teal in the Saskatchewan River Delta. J. Wild. Manage. 33: 77-87.

ESCH, G. W., HAZEN, T. C., and AHO, J. M. 1977. Parasitism and $r$-and K-selection. In Regulation of parasite populations. Edited by G. W. Esch. Academic Press, New York and London. pp. 9-62.

GARCIA, L. S., and Ash, L. R. 1979. Diagnostic parasitology. Clinical laboratory manual. 2nd ed. C. V. Mosby Co., St. Louis, Toronto, and London.
GARKAVI, B. L. 1949. Study of the development of the nematode Streptocara crassicauda (Creplin, 1829), a parasite of domestic and wild ducks. [In Russian.] Dokl. Akad. Nauk SSSR Ser. Biol. 69: $421-424$.

GiBSON, G. G. 1968. Species composition of the genus Streptocara Railliet et al., 1912 and the occurrence of these avian nematodes (Acuariidae) on the Canadian Pacific coast. Can. J. Zool. 46: 629-645.

HolmEs, J. C. 1979. Parasite populations and host community structure. In Host-parasite interfaces. Edited by Brent B. Nickol. Academic Press, New York. pp. 27-46.

KARLOVIC, M., RICHTER, S., and ALERAJ, Z. 1959. Streptocarosis in the Japanese goose (Sygnopsis sygnoides L.). Vet. Ark. 30: 7-12.

KinSELlA, J. M., and ForReSTER, D. J. 1972. Helminths from the Florida duck Anas platyrhynchos fulvigula. Proc. Helminthol. Soc. Wash. 39: 173-176.

KovalEnKo, I. I. 1961. A study of life cycles of some helminths of domestic ducks raised on farms along the Azov sea coast. [English translation.] Dokl. Akad. Nauk SSSR Biol. Sci. Sect. 133: 597-598.

LABERGE, R. J. A., and MCLAughlin, J. D. 1989. Hyalella azteca (Amphipoda) as an intermediate host of the nematode Streptocara crassicauda. Can. J. Zool. 67: 2335-2340.

LANCASTER, M. B. 1973. The occurrence of Streptocara sp. in ducks in Britain. Vet. Rec. 92: 261-262.

MASON, R. W. 1988. Laryngeal streptocariasis causing death from asphyxiation in ducks. Aust. Vet. J. 65: 335-336.

MCDONALD, M. E. 1969. Catalogue of helminths of waterfowl (Anatidae). U.S. Fish Wildl. Serv. Spec. Sci. Rep. Wildl. No. 126.

MCLAughlin, J. D., and MCGuRK, B. P. 1987. An analysis of gizzard worm infections in fall migrant ducks at Delta, Manitoba, Canada. Can. J. Zool. 65: 1470-1477.

MCLELlaND, J. 1979. Digestive system. In Form and function in birds. Edited by A. S. King and J. McLelland. Academic Press, New York and London. pp. 70-181.

QuORTRUP, E. R., and SCHILLINGER, J. E. 1941. Three thousand wild bird autopsies on western lake areas. J. Am. Vet. Med. Assoc. 99: 382-387.

RODGERS, J. P., and KORSCHGEN, L. J. 1966. Foods of lesser scaups on breeding, migration and wintering areas. J. Wild. Manage. 30: $258-264$.

STERnER, M. C., and STACKhouse, L. 1987. Parasitic ulcerative ventriculitis in mallards (Anas platyrhynchos). J. Wildl. Dis. 23: 680-682.

SUGDEN, L. 1973. Feeding ecology of pintail, gadwall, American widgeon and lesser scaup ducklings. Can .Wildl. Serv. Rep. Ser. No. 24.

Swanson, G. A., MEYER, M. I., and SERiE, J. R. 1974. Feeding ecology of breeding blue-winged teals. J. Wildl. Manage. 38: 396-407.

Thul, J. E., Forrester, D. J., and ABERCROMBIE, C. L. 1985. Ecology of parasitic helminths of wood ducks, Aix sponsa, in the Atlantic flyway. Proc. Helminthol. Soc. Wash. 52: 297-310.

Wallace, B. M., and PENCE, D. B. 1986. Population dynamics of the helminth community from migrating blue-winged teal: loss of helminths without replacement on the wintering grounds. Can. J. Zool. 64: 1765-1773.

Wilkinson, J. N., CANARIS, A. G., and Broderson, D. 1977. Parasites of waterfowl from southwest Texas: 1 . The northern cinnamon teal, Anas cyanoptera septentrionalium. J. Wildl. Dis. 13: 62-63. 